\title{
Implementation of Controller Structures in FPGA Platform
}

\author{
S Meena, K.Chitra, T Ramkumar, G Richie Roberts
}

\begin{abstract}
Field Programmable Gate Arrays are recently replacing general purpose microcontrollers in implementation of digital control systems. This paper includes the proposal of implementing complex controller structures in a Field Programmable Gate Array (FPGA). Till recent, PID controllers are implemented in FPGA Platform. PID controllers are simple, reliable, versatile feedback mechanisms used in most control systems. To reduce various undesirable effects on the output such as overshoot, some variants in the conventional PID controllers, such as the I-PD and IMC are also used. Here all these control controller structures are implemented in MATLAB, compared for best performance and run in the FPGA.
\end{abstract}

Index Terms: PID controller, I-PD controller, IMC controller, FPGA, Xilinx ISE 14.7 Design tools.

\section{INTRODUCTION}

FPGA-based controllers are widely used for their elevated speed, power efficiency and advanced functions. Digital feedback systems like magnetic bearings, PWM inverters, induction motors, AC/DC converters, variable-speed drives, and anti-windup compensation of controllers are already in use in FPGA Platform. FPGA-based platforms can do concurrent operations. Hence, simultaneous design of digital controllers can be made.

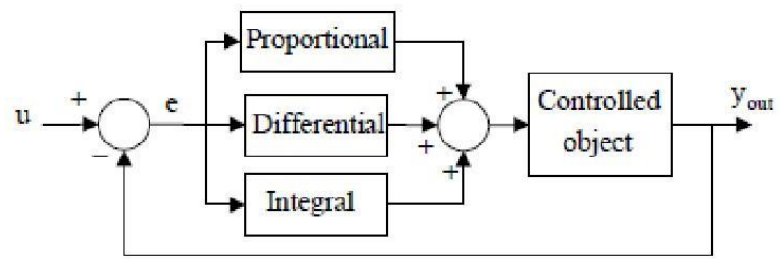

Fig 1.1 PID Controller

A PID controller evaluates the difference between a fixed set point and the process variable and computes the error values. By using a manipulated variable, which is proportional to the computed error signal the PID controller controls the output of a system thereby minimizing the error[2].

Revised Version Manuscript Received on Jun 20, 2019.

S. Meena, Electronics and Instrumentation Engineering, St. Joseph's College of Engineering, Chennai, India.

K.Chitra,SENCE,VIT,Chennai,India

T. Ramkumar, Electronics and Instrumentation Engineering, St. Joseph's College of Engineering, Chennai, India.

G. Richie Roberts, Electronics and Instrumentation Engineering, St. Joseph's College of Engineering, Chennai, India.
Proportional along with integral and derivative values is involved in a PID controller. They are denoted as simply P,I and $\mathrm{D}$. In aspects of time, these can be understood that $\mathrm{P}$ is based on the present error, I is based on already available errors and D anticipates any probable future occurrence of errors, based on present behaviour[2]. With these three actions the final control element such as opening or closing valves, damper, or the amount of power supply, etc.,

Previously, the implementation of FPGA was based on the usage of numerous multipliers and adders and was not focused on optimized usage of hardware and hence was not efficient. It required a numerous multipliers and adders. In the old multiplier-based controllers the blocks take up to $64 \%$ usage of the chip.

A new idea of implementing the I-PD and also IMC control structures in an FPGA. It is made into application after passing through these general phases: 1) Software Modelling Phase where the design of digital control systems is carried out in software like Matlab / Simulink, 2) Hardware Implementation, to obtain real-time observation. Using modules, the design can be ported into environments such as the Matlab / Simulink, thus greatly reducing the developing time for designers.

The Integral - Proportional and Differential controller is an improvisation of a PID controller which is developed so as to minimize the effect of sudden change in the set point on the controller output. Internal Model Control (IMC) provides a procedure for design in accordance with many modern control techniques, the Q-parameterization concept. This made IMC controllers particularly popular in all industrial applications. Also, the IMC showed greater performance than all controllers. This showed greatly reduced oscillations than the conventional models of controller structures.

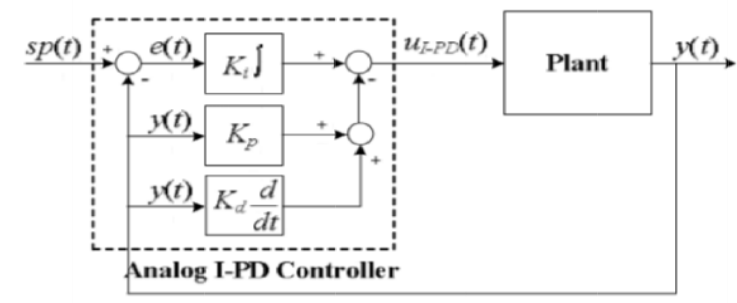

Fig 1.2 I-PD controller

Published By: 


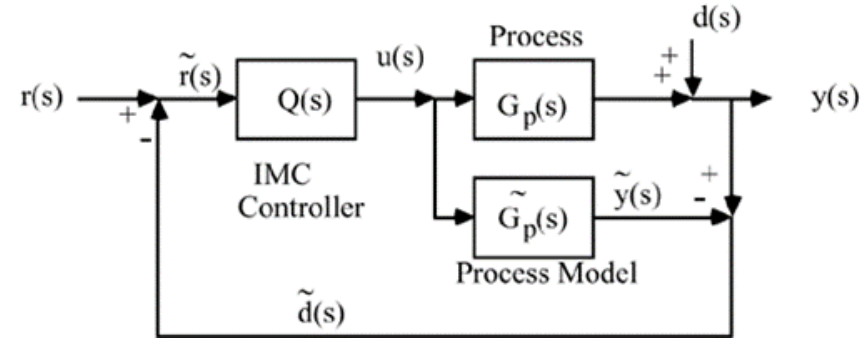

Fig 1.3 IMC Controller

IMC is also helpful in assessing the fundamental necessities associated with feedback control, such as determination of the effect of non-minimum phase elements on achievable control performance. Since the complication of the IMC controller depends on which order the model belongs to, and other performance requirements, the IMC design procedure is helpful in determining when simple feedback control structures (such as PID controllers) are enough.

\section{IMPLEMENTATION OF TEST FUNCTIONS IN MATLAB}

The two processes considered for analysis are stable second order and a boiler drum level process. Both the processes are tested with the various structures such as PID, I-PD and IMC based PID. The time domain specifications and the performance indices are compared and the optimized values are identified.

\section{2.(a). Example 1:}

A stable second order system is considered.

$$
y 1=\frac{2 e^{-1 s}}{50 s^{2}+15 s+1}
$$

The above said process is implemented in all PID, I-PD and IMC control structures.

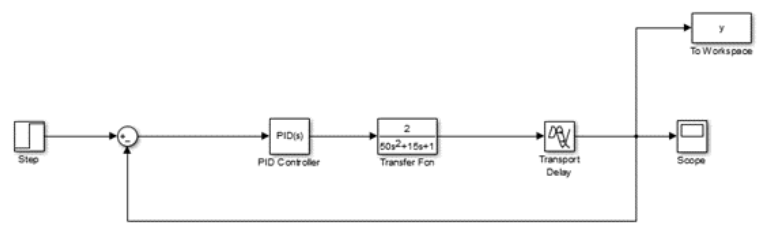

Fig 1.4 Simulink of T.F 1

The performance measures are tabulated in the table 1.1 and the corresponding responses are are given in fig 1.5 .

\begin{tabular}{|c|c|c|c|c|}
\hline \multirow[t]{3}{*}{ yl } & PARAME TERS & PID & I-PD & IMC PID \\
\hline & RISETIME & 34.6728 & 220.9701 & 283.0108 \\
\hline & PE AK TIME & 111 & 971 & 1001 \\
\hline $2 * e^{-s}$ & SE TTLING TIME & 423.6338 & 431.0857 & 532.4004 \\
\hline \multirow[t]{3}{*}{$\overline{(10 s+1)(5 s+1)}$} & ISE & 9.1919 & 8.598 & 12.8209 \\
\hline & IAE & 15.4481 & 12.89 & 25.5214 \\
\hline & ITAE & 232.7793 & 138.3 & 663.0983 \\
\hline
\end{tabular}

Table 1.1 Parameters of response

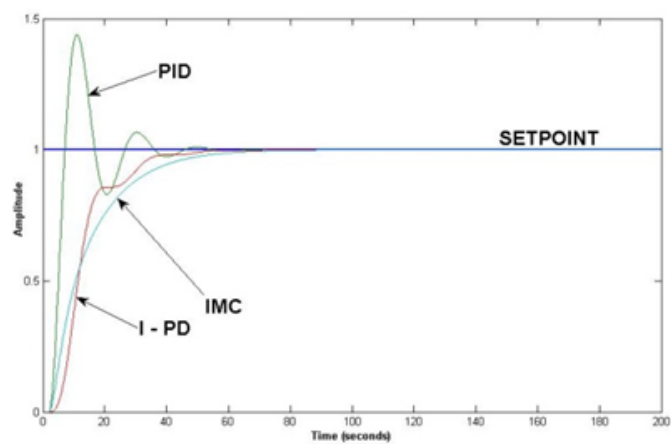

Fig 1.5 Responses of PID, I-PD and IMC

For the example transfer function-1 taken, it is inferred that the IMC control strategy is more optimised comparing with the other control strategies.

\section{IMPLEMENTATION OF REALTIME PROCESS}

For research purposes, a two-tank interacting system commonly used in food processing industries to obtain accurate proportions of mixture is taken. To understand the effect of interaction, we have considered a two-tank system in experiment. The second tank affects the rate of change of level in first tank and vice-versa. The flow through R1 depends on the difference between $\mathrm{h} 1$ and $\mathrm{h} 2$. The analysis started by writing mass balance on the tank. Both the balances of the tanks are the same. The flow head relationship for tank 1 is $\mathbf{q}_{2}=\left(\mathbf{h}_{\mathbf{1}}-\mathbf{h}_{2}\right) / \mathbf{R}_{\mathbf{1}}$

The mass balance equation of tank 1 is

$\left(q_{1}-q_{2}\right)=A_{1} \cdot \frac{d h_{1}}{d t}$

And for tank 2,

$\left(q_{2}-q_{3}\right)=A_{2} \cdot \frac{d h_{2}}{d t}$

The flow head relationships for the two linear resistances $\operatorname{are}^{q_{2}}=\frac{h_{1}}{R 1}$ and $q_{3}=\frac{h_{2}}{R 2}$

At steady state, the flow equation is $\left(\boldsymbol{q}_{1 s}-\boldsymbol{q}_{2 s}\right)=\mathbf{0}$, $\left(q_{2 s}-q_{3 s}\right)=0$.

By solving all the above equations using Laplace transform, the transfer function can be written as,

$\frac{H_{2}(s)}{Q_{1}(s)}=\frac{R_{2}}{\left(\tau_{1} \tau_{2} S^{2}+1\left(\tau_{1}+\tau_{2}+A_{1} R_{2}\right) S+1\right)}$

(7)

\section{Experimental Setup : Two tank interacting system}

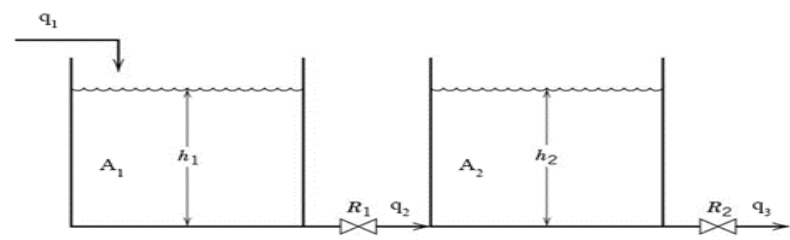

Fig 1.8 Two-tank Interacting System 
Fig 1 .11 Hardware Architecture of FPGA

By substituting the calculated values from the observed data, equation 7 can be written as the overall transfer function and is given by,

$\frac{H_{2}(s)}{Q_{1}(s)}=\frac{0.0462}{25.28 S^{2}+14.5363 S+1}$

(8)

\section{A. IMPLEMENTATION IN MATLAB}

The below transfer function which is obtained for two-tank interacting system is taken.

$$
T . F=\frac{0.0462}{25.28 S^{2}+14.5363 S+1}
$$

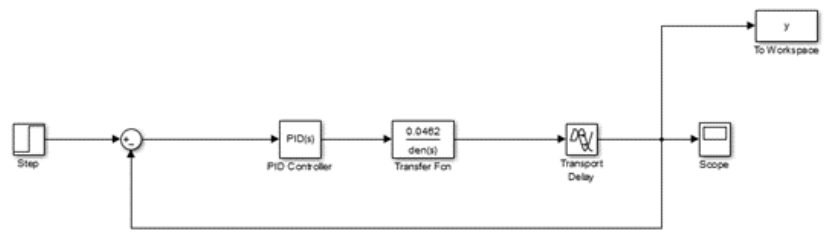

Fig 1.9 Simulink of IMC for Two-tank Interacting System

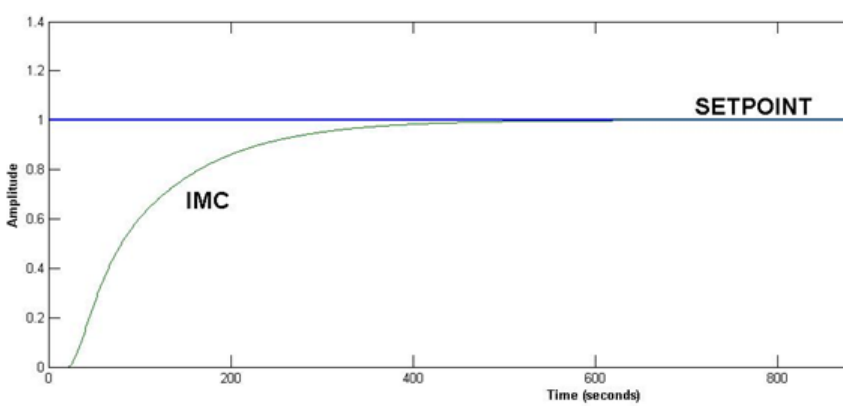

Fig 1.10 Response of IMC

\section{B. IMPLEMENTATION IN FPGA}

FPGA software and hardware integration

FPGAs are supported by development software which convert hardware designs into programming bits which determine the actions of interconnects and Configurable Logic Blocks. The ISE Design Suite Embedded Development Kit includes Platform $\underline{\text { Studio }}$ (XPS), Development Kit (SDK), plug and play IP s.

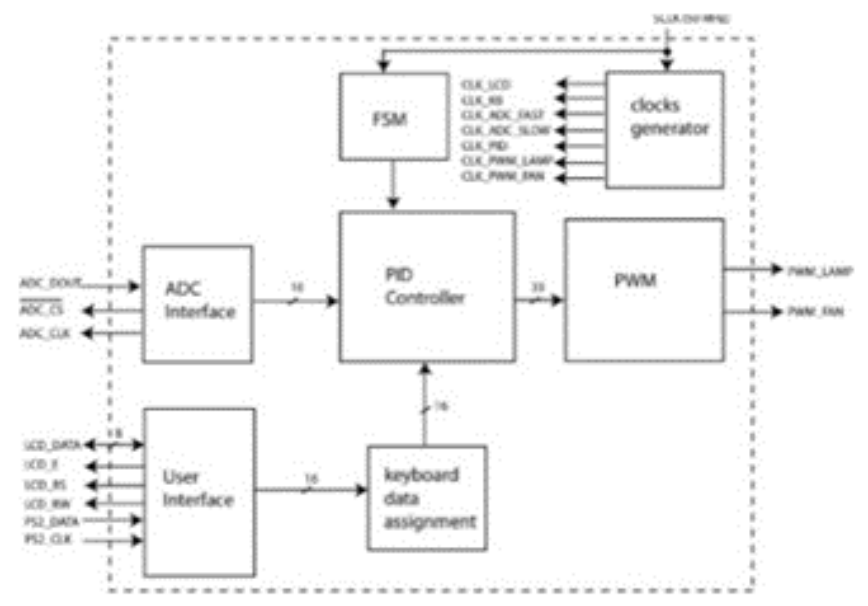

The information for FPGA is programmed as bitstream and the hardware designer provides bitstream and it has been generated in the embedded platform .Programming is the integrating a bitstream into FPGA. In this phase, the FPGA programming is carried out using menu options in SDK, transfering the bitstream to the FPGA.The non-volatile memory has bitstream, and hardware will program FPGA when turned on.

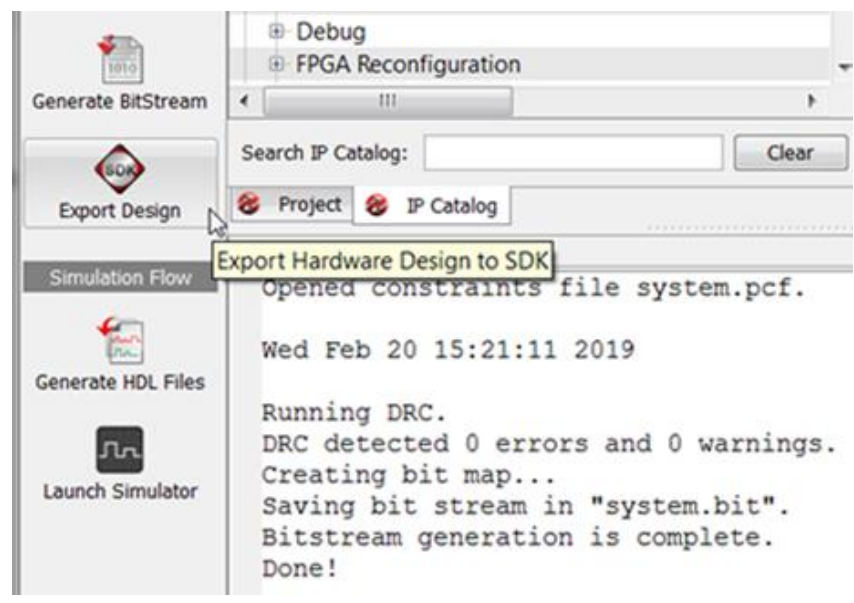

\section{Programming the FPGA}

- $\quad$ Select Xilinx Tools > Program FPGA.

- Bitstream and BMM File will be filled by itself. If necessary, those files need to be specified to upload bitstream to the FPGA

- SDK finds processors, automatically. In Software Configuration, select the executable (.elf) file. select BootLoop from drop-down menu or Browse any ELF file.

\section{- Click Program.}

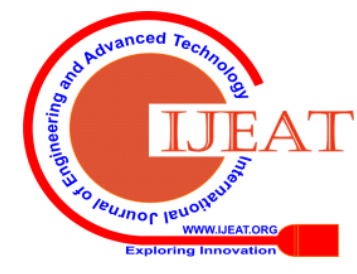



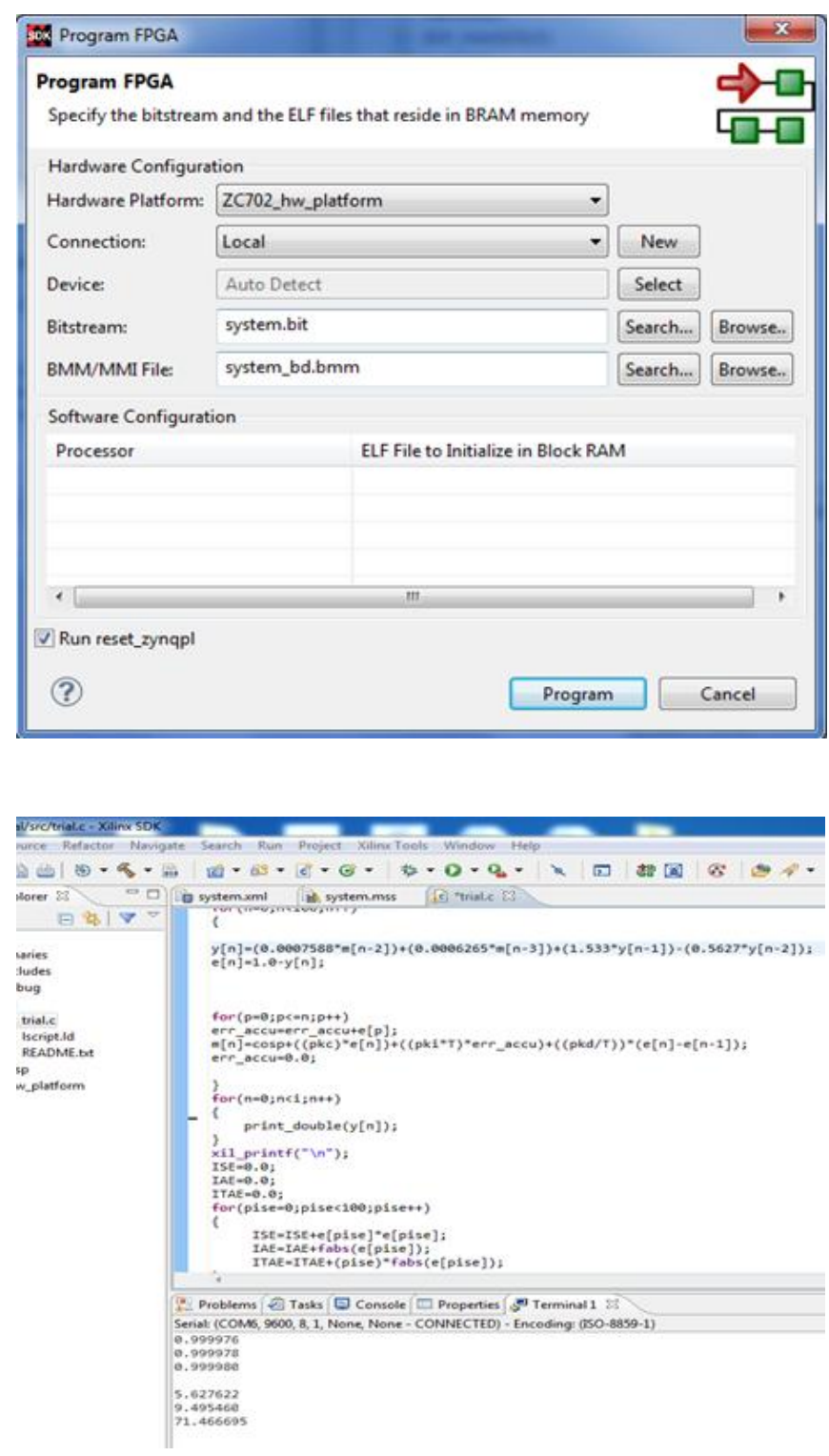

Thus the real time process which was implemented in MATLAB has been converted into FPGA compatible language, integrated with XPS (Xilinx Platform Studio) \& implemented SDK (Software Development Kit) of FPGA platform.

Thus the real time process which was implemented in MATLAB has been converted into FPGA compatible language, integrated with XPS (Xilinx Platform Studio) \& implemented SDK (Software Development Kit) of FPGA platform.

\section{CONCLUSION}

For research purposes, we have taken two test transfer functions and they were successfully implemented in MATLAB for PID, I-PD and IMC control. And it is inferred from the experiments that the IMC control strategy provides better results than other controllers such as lesser rise time, lesser peak time, lesser settling time and lower overshoot. Therefore, The IMC control strategy was taken and implemented for any industrial process (Two-tank interacting system) in FPGA platform successfully. It is also inferred that we can obtain higher quality solution with better computational efficiency in FPGA

\section{REFERENCES}

1. V.Rajinikanth and K.LathaI-PD Controller Tuning For Unstable System Using Bacterial Foraging Algorithm:A Study Based On Various Error Criterion, Hindawi Publishing Corporation Applied Computational Intelligence And Soft Computing Volume 2012, Article Id 329389, 10 Pages Doi:10.1155/2012/329389.

2. P.A. BalakrishnanOptimization Of I-PD Controller For A FOLIPID Model Using Particle Swarm Intelligence, International Journal Of Computer Applications (0975 - 8887) Volume 43- No.9, April 2012.J.

3. Morimasa Ogawa And Tohru Katayama A Robust Tuning Method For I-PD Controller Incorporating A Constraint On Manipulated Variable, Trans. Of The Society Of Instrument And Control Engineers Vol.E-1, No.1, 265/273 (2001).

4. S J Suji Prasad Optimization Of I-PD Controller Parameters With Multi Objective Particle Swarm Optimization, Journal Of Theoretical And Applied Information Technology 20th August 2014. Vol. 66 No.2.

5. Gao, Ruiyao And O'dwyer, Aidan And Coyle, Eugene: A Non-Linear PID Controller For CSTR Using Local Model Networks. Proceedings Of The IEEE 4th World Congress On Intelligent Control And Automation (Wcica 2002), Shanghai, China, 10-14 June.

6. A Nassirharand, N Hoq,H S TzouDesign Of Nonlinear PID Controllers Using System Step Response.

7. Poonam M BaikarDesign Of PID Controller Based Information Collecting Robot In Agricultural Field ,International Journal Of Advanced Research In Electrical, Electronics And Instrumentation Engineering, Vol. 3, Issue 8, August 2014.

8. Meena S, Chitra K. A New approach of PID tuning for Nonlinear SISO system based on Particle Swarm Optimization Techniques.International Journal of Applied engineering Research 2014;9(23):-21701-11.

9. S.Meena ,K.Chitra, R.VijayAnand. Development of I-PD controller on Embedded platform. International Conference on Signal Processing, Communication, Power and Embedded Sysytems. (Scopes- 2016).

10. K.J. Astrom and B. Wittenmark, Computer Controlled Systems, Prentice Hall, New Jersery, USA, 1997.

11. F. Krach, B. Frackelton, J. Carletta and R. Veillette, "FPGA-Based Implementation of Digital Control for a Magnetic Bearing," American Control Conference, Vol.2, pp. 10801085, June 2003.

12. S.L. Jung, M.Y. Chang, J.Y. Jyang, L.C. Yeh, Y.Y. Tzou, "Design and Implementation of an FPGA-Based Control IC for AC-Voltage Regulation," IEEE Trans. on Power Electronics, Vol. 14, pp. 522-532, May 1999.

13. S. Ferreira, F. Hafner, L.F Pereira, F. Moraes, "Design and Prototyping of Direct Torque Control of Induction Motors in FPGAs, " IEEE Symposium on Integrated Circuits and Systems Design, pp. 105-110, Sept. 2003.

14. F. Ricci, H. Le-Huy, "An FPGA-Based Rapid Prototyping Platform For Variable-Speed Drives”, IEEE Industrial Electronics Society Annual Conference, vol.2, pp. 1156-1161, Nov. 2002.

\section{Authors ProfiLe}

Mrs. S Meena has completed her B.E in National Engineering College, Kovilpatti and her M.E from Sathyabama University with specialization in Electronics \& Control. She has 13 years of experience in teaching. Her areas of research are Process control and embedded systems.

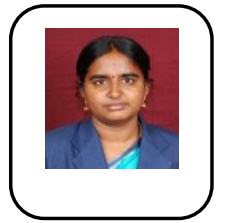

K CHITRA: Currently Dr. K. Chitra is working as a Professor, in the SENSE at VIT, Chennai. Dr. K. Chitra received her B.E. Degree in Electronics and communication Engineering from Bharathiar University, Coimbatore in 1990, M.E. Degree in Applied Electronics from Bharathiar University in 1992 and Ph.D. degree in Optical Communication from Anna University Chennai in 2008. Dr. K.Chitra has spent her 26 years of experience in teaching and

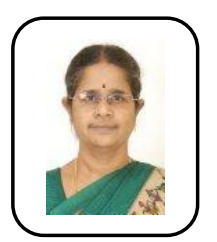
guiding projects for undergraduate and postgraduate students. Dr. K. Chitra has added 15 international publications to her credit. She has few funded projects from Government of India. Dr. K. Chitra's areas of interests include optical communication, optical networks, wireless sensor and computer networks, Biomedical Engineering and microwave Engineering. 
T Ramkumar is currently pursuing final year, Bachelor of Engineering in Electronics and Instrumentation at St. Joseph's College of Engineering, Chennai. His area of interests includes Process Control, Industrial Instrumentation, Embedded Systems and VLSI Design.

G Richie Roberts is studying his final year of Bachelor of Engineering in Electronics and Instrumentation, at St. Joseph's College of Engineering, Chennai. His area of interests includes Process Control, Linear Integrated Circuits, C programming and Embedded Systems. 